\title{
Los rasgos de la ética del humor Una propuesta a partir de autores contemporáneos
}

\author{
JUAN CARLOS SIURANA APARISI \\ Universidad de Valencia (España) \\ Juan.C.Siurana@uv.es
}

\begin{abstract}
Resumen
Destaco algunas de las aportaciones de autores contemporáneos que han abordado el tema del humor desde un punto de vista ético, principalmente: Ronald de Sousa, Joseph Boskin, John Morreall, Simon Critchley y Vittorio Hösle. Partiendo de su pensamiento, defiendo que la «ética del humor» tiene, al menos, las siguientes características: nos ayuda a reconocer los valores éticos en los que realmente creemos, detecta el humor éticamente incorrecto que mantiene estereotipos, fomenta el desarrollo de virtudes, critica los vicios de la sociedad contribuyendo a construir una sociedad más ética, y justifica con razones adecuadas la risa que trata de mejorar éticamente a la sociedad.
\end{abstract}

Palabras clave: ética del humor, humor ético, filosofía del humor, virtudes.

\section{The features of the ethics of humor A proposal from contemporary authors}

\begin{abstract}
I emphasize some of the contributions of contemporary authors that deal with the issue of humor from an ethical perspective, mainly: Ronald de Sousa, Joseph Boskin, John Morreall, Simon Critchley and Vittorio Hösle. Starting from their thoughts I defend that the «ethics of humor» has, at least, the following features: it helps us to recognize the ethical values in which we really believe, it detects the ethically incorrect humor that maintains stereotypes, it promotes the development of virtues, it criticize the vices of the society contributing to build a more ethical society, and justifies with adequate reasons the langhing that tries to improve ethically our society.
\end{abstract}

Key words: ethics of humor, ethical humor, philosophy of humor, virtues.

Doctor Europeo en Filosofía por la Universitat de València (España). Profesor Titular de Filosofía Moral en la misma universidad. Autor de los libros: Una brújula para la vida moral (2003), Voluntades anticipadas. Una alternativa a la muerte solitaria (2005), La sociedad ética. Indicadores para evaluar éticamente una sociedad (2009), y Los consejos de los filósofos. Una introducción a la bistoria de la ética (2011).

Este trabajo se inserta en las actividades del grupo de investigación de excelencia PROMETEO/2009/085 de la Generalitat Valenciana y de la Red de Excelencia ISIC 2012/017 de la Generalitat Valenciana. Es un resultado del proyecto de investigación con número de expediente PCC-8/13 titulado "Los efectos del buen humor en el grado de autonomía de los pacientes en la fase final de la vida", concedido por la Agencia Valenciana de Salud, Conselleria de Sanitat, Generalitat Valenciana, en el marco de las ayudas para la realización de proyectos de investigación para la mejora de la atención del paciente crónico complejo y del paciente susceptible de cuidados paliativos, a desarrollar durante el año 2013. 


\section{Introducción}

En este artículo defiendo que el humor tiene un gran potencial para la mejora ética de los seres humanos y de las sociedades. Pero el humor también puede dañar si se practica incorrectamente. Por eso es necesario construir una «ética del humon». Para elaborar una ética del humor podemos partir de los filósofos clásicos, en los que encontramos muchas referencias importantes a este tema, tarea a la que me he aproximado en artículos anteriores (Siurana, 2012a). En el presente artículo, después de realizar algunas distinciones terminológicas relevantes sobre nuestro objeto de estudio y mostrar su relevancia ética, destaco varias de las aportaciones de los principales autores que han abordado el tema del humor desde una perspectiva ética en la actualidad. Los autores que analizo principalmente son: Ronald de Sousa, Joseph Boskin, John Morreall, Simon Critchley y Vittorio Hösle.

Selecciono aportaciones de estos autores que se complementan entre sí y, a partir de ellas, realizo una propuesta de algunos de los rasgos que cabe atribuir a la «ética del humor», una ética aplicada que está en proceso de construcción.

\section{El sentido del humor ético como equilibrio con uno mismo y con los demás}

\subsection{El humor percibe o muestra lo cómico, provocando hilaridad}

Partiendo de las conclusiones de otros trabajos que he publicado con anterioridad (Siurana, 2012b y 2013), considero que, para delimitar el objeto de estudio de este artículo ${ }^{1}$, podemos comenzar definiendo de este modo cinco conceptos nucleares:

1.- El humor es la capacidad para percibir o mostrar algo como cómico y, como consecuencia de ello, para activar la emoción de la hilaridad.

2.- La bilaridad es la emoción placentera relacionada con la alegría que se expresa mediante la sonrisa o la risa, provocada principalmente por algo cómico que el humor es capaz de percibir, aunque puede estar provocada por otras causas, como las cosquillas.

\footnotetext{
Un libro imprescindible, en todo caso, para el conocimiento del humor, es sin duda el de Martin, 2008.
} 
3.- La sonrisa es la expresión física de hilaridad de intensidad baja (se arquean los labios).

4.- La risa es la expresión física de hilaridad de intensidad alta (carcajadas moderadas) o de intensidad muy alta (carcajadas estrepitosas).

5.- La comicidad es la cualidad de los seres vivos y cosas que, al ser captada por alguien con capacidad para percibirla, provoca la emoción de la hilaridad. A esta cualidad también se le llama gracia, y a lo que la posee, cómico o gracioso.

Para establecer la relación entre estos cinco conceptos, podemos concluir que el bumor percibe o muestra lo cómico, provocando hilaridad, que se expresa a través de la sonrisa o la risa.

\subsection{El sentido del humor ético es una actitud positiva ante la vida}

El concepto del «humon» se utiliza en muchas ocasiones para referirse a un «sentido» (Carbelo, 2008: 44) que poseemos junto a otros, por similitud con la vista, el oído, el olfato, el gusto y el tacto. Siguiendo con esa analogía, cabe, por tanto, distinguir entre lo que ahora vemos y nuestra capacidad de ver, entre lo que ahora oímos y nuestra capacidad de oír. Lo mismo ocurre con el humor.

La percepción de lo cómico es un fenómeno puntual, que afecta a un hecho concreto, en un momento concreto, y que, por sus características, es capaz de hacernos sonreír o reír.

El sentido del humor, en cambio es una capacidad para percibir tanto ese fenómeno, como otros muchos, como cómicos. Y la posesión de esa capacidad nos permitirá también hacer o decir cosas graciosas, en la medida en que cultivemos nuestras destrezas para hacerlo.

Pero el sentido del humor es más complejo que los otros sentidos básicos. Un ejemplo de esa complejidad es que la posesión de esta capacidad y su ejercicio habitual, llevan a convertir el sentido del humor en una «actitud ante la vida».

El sentido del humor está relacionado con vivir con alegría la vida a partir de lo que sucede en ella.

Puesto que es una «actitud ante la vida» es de gran interés para la ética. Lo importante, desde el punto de vista ético, es aprender a cultivar ese sentido del humor éticamente, para que esa «actitud ante la vida» sea realmente armoniosa con aquellos que nos rodean y que, por tanto, la alegría que produce no esté basada, por ejemplo, en la percepción de la injusticia como algo agradable, sino en valores éticamente positivos. 


\subsection{El sentido del humor ético contribuye a la armonía con uno mismo y con los demás}

Begoña Carbelo (2008: 45), enfermera, nos dice: «La persona que tiene sentido del humor tiene un alto grado de autoestima, lo que le permite ver sus imperfecciones y no desea sentirse superior a otros». Puesto que hay personas que ríen de otras, Carbelo se estaría refiriendo, implícitamente, a las ventajas de disponer de un «sentido del humor ético». Carbelo, que no habla explícitamente de «humor ético», soluciona la cuestión de cómo enfrentar el hecho de su uso inapropiado diciendo que «no deben considerarse como un ejemplo de humor los chistes agresivos, porque el humor nunca sería agresivo». Pero no aclara cómo deberíamos llamar a ese fenómeno si no podemos llamarlo «humor». Creo que resulta más adecuado para la conceptualización del fenómeno distinguir entre el «humor» en general, y el «humor ético» en particular.

Garanto define el humor de este modo: «es el estado de ánimo más o menos persistente y estable, que baña equilibradamente sentimientos, emociones, estados de ánimo o corporales, surgentes del contacto del individuo (corporalidad y psique) con el medio ambiente y que capacita al individuo para, tomando la distancia conveniente, relativizar críticamente toda clase de experiencias afectivas que se polaricen, bien sea hacia situaciones eufóricas, bien sea hacia situaciones depresivas» (Garanto, 1983). Creo que Garanto, en realidad, con esta definición, ofrece algunas de las características del «humor ético», cuyos rasgos conviene aclarar.

El humor ético tiene que ver con la armonía con uno mismo y con los demás, pero, ¿cómo actúa este tipo de humor para conseguir la armonía? En otros trabajos he recordado las teorías clásicas sobre las causas del humor (teoría de la superioridad, teoría de la incongruencia y teoría de la liberación de la tensión), y he resumido las aportaciones de los filósofos clásicos a este tema, tarea que ha realizado con más profundidad John Morreall (1987). En este artículo es mi intención reflexionar sobre las aportaciones de cinco autores contemporáneos para la construcción de una ética del humor, los autores son: Ronald de Sousa, Joseph Boskin, John Morreall, Simon Critchley y Vittorio Hösle. A partir de sus aportaciones intentaré mostrar en qué consiste el «humor ético», tan relevante para una «ética del humor». 


\section{Ronald de Sousa: La risa refleja las actitudes de una persona}

\subsection{La emoción de la hilaridad puede ser éticamente evaluada}

Ronald de Sousa ha elaborado una propuesta según la cual, «las emociones pueden ser racionalmente evaluadas» (De Sousa, 1987: 227). $Y$ en ese marco evalúa éticamente la risa.

La risa, tal y como la entiende este autor, es una respuesta a lo que los objetos formales tienen de divertido, gracioso, cómico o ridículo. Él lo aglutina todo con el nombre de lo divertido (the Funny).

Él está interesado en lo divertido, en nuestra respuesta emocional a ello, y en la posibilidad de evaluar racionalmente - en este caso, éticamente- dicha respuesta.

En la medida en que nosotros pensamos que, en ocasiones, es irracional o moralmente incorrecto reír, cabe intentar racionalizar los principios detrás de tales valoraciones para construir lo que De Sousa llama una «Ética de la risa».

Así pues, su trabajo sobre la ética de la risa, que es, sobre todo, una ética de la hilaridad, cabe entenderse en el marco de una discusión más general sobre el papel de las emociones en la vida moral.

Su idea es que algunos principios de racionalidad constriñen cuáles son las emociones que pueden coexistir en relación al mismo objeto. La razón nos indica, en ocasiones, que no es correcto reír, limitando, por tanto, la emoción de la hilaridad o, al menos, la expresión de la misma mediante la risa. Así, por ejemplo, todos somos capaces de percibir la diferencia entre reír de alguien y reír con alguien. En muchos casos, la razón limitará a nuestra emoción para impedir que riamos de alguien.

Según Ronald de Sousa, una ética de la risa, basada en el sentido común, defendería lo siguiente: «Ríe de lo que es divertido, no te rías de chistes verdes, no te rías de los lisiados (a menos que tú seas uno de ellos), y muestra respeto. Mostrar respecto significa no reírse, desternillarse, descuajaringarse, troncharse, o incluso mofarse cuando es demasiado triste, cuando sería descortés hacerlo, cuando ofendería una memoria sagrada, y cuando podría ser tomado como un insulto a la madre, al país o a la religión» (De Sousa, 1987: 228).

Pero unos pocos preceptos no constituyen una ética. El autor se pregunta si puede algo llamarse propiamente una «ética de la risa».

\subsection{La risa refleja el carácter de una persona}

Para determinar si nuestras actitudes hacia la risa pueden ser gobernadas por principios genuinamente morales, echemos un vistazo a 
los diferentes tipos de consideración moral: En ética suele distinguirse entre la ética de la intención (lo importante es la intención de quien realiza una acción), y la ética de la responsabilidad o de las consecuencias (lo importante son las consecuencias reales de la acción) (Cortina \& Martínez, 1998).

Tenderíamos, por tanto, a pensar que para una ética de la risa también podría ser relevante la distinción entre estos dos tipos de ética. De Sousa las tiene en cuenta, pero considera más importante la referencia a lo que él llama los síntomas y los procedimientos.

\section{1.- Los sintomas: La risa genuina muestra cuál es nuestro carácter}

Hay casos en los que podemos decir: «Si tú eres capaz de reír de algo como eso, tú debes ser insensible, grosero o cruel».

Para el kantiano lo importante es la intención de la risa. Pero el hecho de que la risa surja casi sin darnos cuenta, como un rasgo de nuestro carácter, como algo natural integrado en nuestra personalidad, hace inapropiado que podamos referirnos a las intenciones del reír.

Según De Sousa, si podemos preguntar «¿qué intentabas alcanzar riendo?» es que no hubo una risa genuina. La risa genuina no tiene una intencionalidad, se ríe de lo que nos causa gracia, de lo que nos resulta cómico. Y dependerá de cuál sea nuestro carácter el que la risa surja o no. Entonces reír es síntoma de algo. Demuestra cuáles son los rasgos de nuestra personalidad, de nuestro carácter.

2.- Los procedimientos: Reimos genuinamente de aquello que realmente nos hace gracia, pero podemos evaluar éticamente por qué nos hace gracia

De Sousa establece un paralelo entre la consideración de los síntomas del carácter al reír de algo con lo que él llama la «ética de la creencia».

De Sousa nos dice que la creencia, como la risa, no es típicamente voluntaria ${ }^{2}$. Si alguien cree en algo con algún propósito entonces la creencia deja de ser genuina.

La evaluación ética de la creencia se realiza en función de los procedimientos en los que se origina. Así, creer en algo porque las consecuencias de creer en ello serían buenas, es siempre una violación de la «ética de la creencia». Dicho de otro modo: Si alguien cree que el sol

2 Creo que es conveniente matizar esta afirmación de De Sousa. Lo que yo defiendo - y creo que él también da a entender más adelante- es que en un nivel superficial la risa es involuntaria, es decir, cuando algo nos hace gracia prácticamente no podemos evitar reír, pero en un nivel más profundo la risa es la expresión de nuestro carácter, que sí forjamos de acuerdo a nuestra voluntad. En ese sentido más profundo, la risa sí que es voluntaria, y por eso podemos educar en el humor ético. 
gira alrededor de la Tierra porque de ese modo se sentirá más aceptado por su comunidad, sabe en el fondo que no cree en eso, porque ese no es un procedimiento correcto para aceptar una creencia. La creencia se encuentra en el convencimiento interno de que algo es cierto y en las razones que uno tiene para llegar a ese convencimiento.

Lo mismo puede decirse de la «ética profesional» (Cortina \& Conill, 2000; Correa \& Martínez, 2010) (ya sea de los médicos, las enfermeras, los empresarios o los jueces). En todas ellas hay reglas sobre los mejores procedimientos para desarrollar del modo más ético dicha profesión. Un buen profesional hace las cosas bien porque cree que tiene que hacerlo así, porque siente que así es como actúa un buen profesional. Para ello sigue una serie de principios de ética profesional en los que cree internamente, principios que no están sujetos a los caprichos de sus preferencias individuales. ${ }^{3}$. Por eso, cuando los transgrede, surge el remordimiento de conciencia, al haber actuado en contra de algo en lo que creía internamente.

De Sousa explora, sobre todo, la dimensión de los sintomas y los procedimientos para elaborar su propuesta de «ética de la risa» (De Sousa, 1987: 233), es decir, explora cuál es el carácter que muestra una persona al reír y las razones que justifican el tener ese carácter.

\subsection{No podemos reír maliciosamente de alguien si nuestro carácter es ético}

De Sousa se centra en investigar un tipo de risa que es susceptible de condena moral: la risa maliciosa o risa «phtónica» (phthonic laughter). Toma prestada la palabra phthonos de Platón ${ }^{4}$, que significa algo así como «envidia maliciosa»: tiene que ver con algo malo, y con la ambigüedad entre la identificación y rechazo que caracteriza a los celos. Platón la aplica al tipo de risa típicamente experimentada en algún espectáculo ridículo. El ridículo malicioso se dirige especialmente contra nuestros enemigos y presupone que los que ríen comparten nuestra misma animadversión hacia ellos.

Cuando uno cuenta un chiste sexista o racista se presupone que el que escucha comparte esas actitudes. El elemento «phtónico» necesita respaldo. Nos hace reír solamente si compartimos esas actitudes. Y lo interesante para De Sousa es que no podemos encontrar algo divertido

\footnotetext{
3 Por ejemplo, para los principios en el ámbito sanitario, cf. Beauchamp \& Childress, 1999.

4 Para las referencias al humor y la risa en Platón, cf. Platón: Filebo, 48-50; República, L. III, 388e.
} 
sólo imaginando que compartimos las actitudes presupuestas, debemos compartirlas internamente. Este autor afirma que no se puede pensar con valores éticamente incorrectos si no se tienen.

De Sousa afirma también que pensar que algo es intrínsecamente divertido es una actitud, y reír de un chiste "phtónico» revela que se poseen actitudes reales poco éticas. El chiste «phtónico» descansa en actitudes, $\mathrm{y}$ «las actitudes son creencias que uno no puede adoptar hipotéticamente» (De Sousa, 1987: 241).

Esto, considera De Sousa, revela una característica interesante de la categoría de las actitudes emocionales: su naturaleza no hipotética.

\subsection{Incluso cuando reímos solos imaginamos a otros riendo con nosotros, compartiendo nuestros valores morales}

La naturaleza no hipotética de las actitudes está relacionada con otra de sus características: su naturaleza social. Un aspecto de este factor es la relatividad social de los chistes. Esto forma el tema de una de las observaciones fundamentales de Bergson (2008) sobre lo cómico. Los chistes son relativos a la sociedad. La risa siempre tiene un pensamiento subconsciente de comunidad, la comunidad imaginaria de los que ríen ${ }^{5}$. Así, De Sousa dice que cuando reímos solos, imaginamos a otros riendo con las mismas actitudes. Un sentido de comunidad puede generar una adopción genuina de actitudes.

\subsection{La risa éticamente incorrecta está basada en valores éticamente incorrectos}

Si la risa está equivocada es porque el compromiso emocional está equivocado. «Lo 'no ético' (...) implica una valoración equivocada de la realidad〉 (De Sousa, 1987: 244). Esto confirma que la ética de la creencia guarda una estrecha relación con la ética de la risa. Como la creencia, «la risa es equivocada cuando está basada en el engaño del yo o de otros» (De Sousa, 1987: 244).

Podríamos decir que donde la actitud presupuesta por un chiste es moralmente cuestionable, entonces contar el chiste o reír de él es también moralmente cuestionable.

\footnotetext{
5 Una ética del humor tiene necesariamente, según yo defiendo, que hacer consciente esa comunidad y anticiparla como idea regulativa para evaluar la altura ética de nuestro humor, de un modo similar a como funciona la comunidad ideal de comunicación en el pensamiento de Karl-Otto Apel (1985). Véase Siurana, 2003.
} 
A menudo, por ejemplo, reímos de estereotipos que son injustos. Los estereotipos son valoraciones equivocadas de la realidad, por eso, una de las preocupaciones de la ética del humor es la de evitar el tipo de risa basada en estereotipos.

\section{Joseph Boskin: E1 humor ético evita mantener estereotipos}

\subsection{Un estereotipo es una imagen mental muy simple, no crítica y con capacidad de mantenerse tenazmente sobre el pensamiento racional}

Walter Lippmann (1922: 89-90) escribió: «Las más sutiles y persuasivas de todas las influencias son las que crean y mantienen el repertorio de los estereotipos. Se nos habla del mundo antes de verlo. Imaginamos la mayoría de las cosas antes de experimentarlas. Y esas percepciones, a menos que la educación nos haya hecho muy conscientes, gobiernan profundamente todo el proceso de percepción».

Lippmann se muestra optimista respecto al potencial de la educación para acabar con los dañinos efectos de estereotipar, pero - al menos, en lo que afecta a los grupos minoritarios y étnicos- su optimismo no ha sido confirmado.

Una vez implantada en el saber popular, una imagen atribuida a un grupo, un tema o un acontecimiento, impregna los sentidos más profundos y afecta profundamente a las acciones y comportamientos.

Un estereotipo es una imagen mental estandarizada representando una opinión ultrasimplificada o un juicio no crítico, y es tenaz en su mantenimiento sobre el pensamiento racional. Consigue su poder por la repetición, con diversas formas, de modo que la imagen que proyecta se vuelve firmemente incrustada en niveles reactivos de pensamiento y acción. Como una parte integral del patrón de una cultura, una imagen, por su propia naturaleza, operará dentro y en muchos niveles de la sociedad.

Tal imagen afecta a los pensamientos y acciones de aquellos que pueden ser conscientes de su existencia. Y, lo que es más importante, influencia a aquellos que no son conscientes. Joseph Boskin (1987: 250) escribe: «No es una exageración afirmar que los estereotipos son tan pertinaces que pueden ser desalojados sólo después de una serie de asaltos poderosos».

Esto se debe a que pasan de una manera oral y visual de una generación a otra. El estereotipo, una vez establecido, crea, su propio folklore, constituye en sí mismo una fuerza centralizadora. 
La imagen puede tener poca relación con la realidad. Gordon Allport en su libro The Nature of Prejudice, afirma que «es posible para un estereotipo crecer desafiando toda evidencia» (Allport, 1954: 185).

La creación de estereotipos es algo nuevo en la historia de la humanidad. Desde el punto de vista de Lippmann, estereotipar se volvió imperativo en la cultura moderna a causa de la naturaleza de la sociedad tecnológica. Las personas en la sociedad contemporánea tienen siempre mucha prisa y muchas cosas que hacer, por lo que tienden a separar mentalmente a la gente. Así, no hay «ni tiempo ni oportunidad para el conocimiento íntimo» (Boskin, 1987: 251). En su lugar nos centramos en un rasgo que designa a un tipo bien conocido, y lo llenamos con el resto de la imagen por medio de estereotipos que llevamos en nuestras cabezas. «Estereotipar simplifica el proceso de percibir a otras personas y cosas» (Boskin, 1987: 251).

\subsection{El estereotipo cómico de Sambo}

En la historia de las relaciones de las razas en los Estados Unidos, los estereotipos han sido particularmente perniciosos. Una de ellas es la historia de Sambo y el Salvaje. Esta historia profundiza en el estereotipo que concibe la inferioridad de una raza o de una cultura sobre otra.

En películas como la de D. W. Griffith «Birth of a Nation» (de 1915) o «Tarzán», los negros son guerreros y brutos sexuales. La supuesta naturaleza violenta de los negros es utilizada por intereses políticos cuando se requiere. El negro como salvaje es una imagen que se repite.

El estereotipo de Sambo se integró en la cultura popular, y su figura consistió principalmente en dos cosas:

1.- Era infantil y cómico, debido a gestos extranjeros y ropas divertidas, era inocente, no se percibía a sí mismo como listo, y era irresponsable.

2.- En otro nivel Sambo era el esclavo natural y sirviente que mostraba las cualidades de paciencia y no violencia, y se esperaba de él responsabilidad.

Se trata, por tanto, de una imagen mental contradictoria. Pero las dos formas separadas se trasladaban a formas teatrales.

Sambo es la alegría. Su alegría se centra en la naturaleza del humor. De todos los grupos étnicos en la cultura americana, sólo los afroamericanos estaban íntimamente vinculados al amplio campo del humor. 
Los irlandeses y los polacos fueron vistos, posteriormente, como gente de la que reírse, pero los afro-americanos han sido el fin del humor durante tres siglos.

Una de las funciones básicas del humor es la de ser una forma de comunicación social, sirviendo tanto para el propósito individual como grupal. Joseph Boskin (1987: 254) escribe: «Como una forma esencial de comunicación social, el humor está integralmente conectado al código cultural de la sociedad».

El código cultural es quizás el aspecto elemental en la estructura social del humor. Para ser entendido y poseer significado, el humor debe, de algún modo, referirse a la experiencia y conciencia de la mayoría.

El estereotipo de Sambo, cuya longevidad reflejó sus funciones profundamente enraizadas, fue una forma esencial de humor hostil. Sambo fue la «persona-máquina» cómica tal y como la describe Bergson (2008), la absurdidad palpable, suscrita por blancos en su intento de preservar una distancia social entre ellos y los negros, para mantener un sentido de superioridad racial, y para prolongar la estructura de clase. Estereotipar a los negros como cómicos en la cultura popular de los Estados Unidos es un ejemplo de la reducción psicológica y cultural. Sambo, pues, ilustra la relación histórica entre estereotipar y hacer humor (Boskin, 1987: 262), algo que debe rechazar una «ética del humor».

Pero la «ética del humor» no solo tiene como tarea la de evitar el humor malicioso o el humor que estereotipa, sino que tiene, sobre todo, un sentido positivo, como formador de virtudes, como veremos a continuación.

\section{John Morreall: Las virtudes del humor}

\subsection{La ética positiva del humor}

Entre los autores que han escrito sobre la ética del humor en la actualidad destaca John Morreall (2009: 90-124), especialmente en su libro titulado Comic Relief. A Comprehensive Philosophy of Humor, que contiene dos capítulos sobre la ética del humor.

Como nos han sugerido los autores anteriores, entre los temas más estudiados que afectan a la ética del humor se encuentran los chistes racistas o sexistas. Para Morreall, aunque la consideración de ese tipo de chistes es claramente importante, no deja de ser una pequeña parte de lo que se ha escrito sobre la dimensión moral del humor en las últimas décadas. En su libro distingue entre dos tipos de ética del humor. la negativa (que defendería la importancia de limitar el humor porque promueve 
vicios) y la positiva (que describe las virtudes morales que pueden fomentarse a través del humor). A continuación dejaremos de lado cuáles son esos vicios que se atribuyen al humor, y mostraremos cuáles son las virtudes que puede fomentar.

\subsection{El humor en el marco de la ética de las virtudes}

Aunque la gran mayoría de las afirmaciones religiosas y filosóficas sobre la risa la han asociado al vicio, algunos la han asociado a estados positivos como la alegría o el gozo. En el Nuevo Testamento, por ejemplo, Jesús parece considerar a la risa en ese sentido positivo cuando afirma: «Bienaventurados los que ahora lloráis, porque reiréis» (Lc 6,21).

Otro sentido positivo de pensar sobre el humor se ha asociado al juego. De acuerdo con Aristóteles, en la vida del ser humano es importante dar un espacio al ocio y la diversión. Algunas personas llevan la diversión al exceso, y a éstos Aristóteles les llama «vulgares bufones». Pero entre la bufonería y la completa seriedad, hay un término medio en el que se encuentra la virtud que lleva a la felicidad, practicando el humor en el momento y lugar correcto, y en el grado adecuado. Esta eutrapelia, o broma amable, este tipo especial de disposición ingeniosa, cuenta como una virtud en su Ética a Nicómaco ${ }^{6}$.

Los comentarios de Aristóteles sobre la eutrapelia no se toman en consideración hasta que, en la época medieval, Tomás de Aquino los adapta a la filosofía escolástica cristiana. En su Suma de Teología, Tomás de Aquino trata sobre el humor y el juego, y su posición se asemeja a la de Aristóteles: Los seres humanos necesitamos descansar ocasionalmente de la actividad seria. El humor y otras formas de juego nos ofrecen ese descanso.

A la persona que tiene la virtud moral asociada con el juego y el humor, Tomás de Aquino la llama un eutrapelos, una persona agradable con una casta de mente feliz que da a sus palabras y hechos un giro alegre $^{7}$.

Morreall se adhiere a la propuesta de Aristóteles y Tomás de Aquino de que el humor puede ser virtuoso. Ambos pensadores entienden la virtud como un tipo de excelencia de la persona, y distinguen entre virtudes intelectuales y éticas. Morreall defiende que el humor puede fomentar ambos tipos de virtudes. Destacaremos, a continuación, su contribución a las virtudes éticas.

\footnotetext{
6 Para revisar la noción de humor en Aristóteles en relación con las virtudes, cf. Aristóteles, Ética a Nicómaco, IV, 8; Poética, V, 1449a.; 1128a.; Retórica, 3, 2.

7 Cf. Tomás de Aquino, Suma de Teología, II-II, q. 168.
} 


\subsection{Las virtudes éticas que promueve el humor}

Según Morreall (2009: 90-124; 2010), el humor promueve las siguientes virtudes éticas:

\section{1.- Paciencia}

Viendo las cosas con sentido del humor no esperamos que ocurran a la velocidad que nos gustaría.

\section{2.- Tolerancia}

El humor correlaciona con la apertura de mente y, en las interacciones sociales, la voluntad de ver las cosas de modo diferente nos hace entender mejor a otras personas, lo que piensan, y cómo actúan. De este modo, el humor puede ayudar a reducir fricciones sociales. Sammy Basu (1999: 147-172) ha examinado cómo el humor promociona la tolerancia religiosa.

Un ejemplo es el de aquel hombre, cuyo padre era judío pero su madre no, y a quien no le dejaban ser miembro de un club de golf en tiempos del nacismo. Pidió hablar con el presidente del club para hacerle una pregunta. La pregunta era la siguiente: «Puesto que soy sólo medio judío, ¿puedo pertenecer al club si sólo juego nueve hoyos?» El presidente comenzó a reír y le admitió en el club.

\section{3.- Amabilidad}

Hacer gracias permite a las otras personas relajarse y no sentirse amenazadas. Una persona que es corregida con gracia es más probable que escuche el mensaje y actúe en consecuencia. Un ejemplo contrario es cuando alguien amenaza a otros con acciones legales cuando se siente injustamente tratado. Esto hace a la gente ponerse a la defensiva, de modo no razonable e incluso hostil.

\section{4.- Humildad}

Cuando uno se ríe de sí mismo puede salvar situaciones conflictivas y es apreciado por los demás.

\section{5.- Perseverancia}

Cuando se combina la humildad con la paciencia, cuando nos vemos desde una perspectiva cómica, es menos probable que nos sintamos superados por la frustración. Thomas Edison intentó más de 10.000 combinaciones de materiales hasta llegar a inventar la bombilla. Cuando se le preguntó si se sentía triste por todos esos intentos fallidos 
respondió: «No, yo simplemente aprendí miles de modos de cómo no hacer una bombilla».

\section{6.- Coraje}

Ocurre cuando la perseverancia opera en situaciones de peligro. Algunos ejemplos evidentes ocurrieron durante el Holocausto. Como cuenta Steve Lipman (1991) en su libro Laughter in Hell, por ejemplo, en los ghettos, la obra principal de Hitler no era conocida por su verdadero título Mein $\operatorname{Kampf(mi~lucha)~sino~por~Mein~} \operatorname{Krampf}$ (mi calambre).

Morreall concluye que el humor promociona muchas virtudes, y aquellos que carecen de este tipo de humor virtuoso están en serio riesgo de ser meros pedantes.

Habiendo aplaudido al humor por su asociación con muchas virtudes, Morreall añade que, no obstante, ese vínculo no es universal. No hay una conexión necesaria entre el humor y las virtudes como no lo hay entre el humor y los vicios. Hay humor que implica egoísmo, intolerancia y crueldad. El humor no es esencialmente ni virtuoso ni vicioso.

De esta afirmación podemos extraer que el humor que fomenta las virtudes es un tipo específico de humor, que en este artículo estamos llamando el «humor ético».

Pero la ética del humor no sólo consiste en reconocer que expresa nuestro carácter (De Sousa), que ha de criticar su uso incorrecto, por ejemplo, en la consolidación de prejuicios (Boskin), y que es el que fomenta virtudes. La ética del humor también tiene, como tarea, la de criticar los vicios de la sociedad y contribuir a la construcción de una sociedad más ética, como puede extraerse de las propuestas de Simon Critchley.

\section{Simon Critchley: el humor auténtico como crítica a los vicios generales}

Simon Critchley (2010) no se presenta como un autor que quiera elaborar una ética del humor, pero de sus trabajos podemos extraer muchas ideas relevantes para configurarla. En este apartado analizaremos su obra titulada Sobre el humor que, según entiendo, contiene muchos elementos valiosos para nuestra tarea. 


\subsection{El chiste auténtico nos hace más libres y transforma la sociedad}

Critchley defiende que «lo que sucede en el humor es una forma de liberación o elevación que expresa algo esencial para lo que Plessner llama 'la humanidad de lo humano'».

El personaje Eddie Waters, el filósofo cómico de la obra Comedians de Trevor Griffiths resume la posición que mantiene también Critchley: «Un auténtico cómico es un hombre atrevido. Se atreve a lo que sus oyentes esquivan y temen expresar. Lo que ve es una especie de verdad sobre las personas, sobre su situación, sobre lo que les hace daño o atemoriza, sobre lo que es duro, sobre todo sobre lo que quieren. Un chiste relaja la tensión, dice lo indecible, cualquier chiste vale. Pero un auténtico chiste, el chiste de un cómico, hace algo más que relajar la tensión, tiene que liberar la voluntad y el deseo, tiene que cambiar de situación》 (Griffiths, 1976: 20).

Los chistes son un juego, en el que se juega con las prácticas aceptadas de una sociedad determinada, mostrando que los patrones aceptados de conducta carecen de necesidad y, por lo tanto, podrían cambiarse. Así, el chiste puede desempeñar una función crítica respecto a la sociedad.

Siguiendo al personaje Eddie Waters, Critchley está interesado por el humor «auténtico». Ese tipo de humor cambia la situación, nos dice algo sobre quiénes somos y la clase de lugar en que vivimos y tal vez nos indique cómo podría cambiar.

\subsection{E1 humor auténtico critica los vicios generales, no los personales}

La mayoría de los chistes, desgraciadamente, son reaccionarios, es decir, forman parte de un humor sexista, que ríe de los marginados o de las minorías étnicas, reforzando con ello las formas de actuación poco éticas de la sociedad.

Pero Critchley defiende el auténtico bumor, y eso supone una exigencia normativa, una distinción entre «buenos»y «malos» chistes, en sentido ético. Critchley (2010: 31) escribe: «En mi opinión, el auténtico humor no perjudica a una víctima específica y siempre contiene una burla de nosotros mismos».

La tarea crítica del humor consiste «en fustigar los vicios que son generales, no personales» (Critchley, 2010: 32). Nadie puede resentirse si se ataca a un vicio que comparten miles de personas. Además, criticar un vicio no es un defecto que no se pueda corregir (como una 
malformación), por lo que el auténtico humor desempeña tanto una función terapéutica como crítica.

\subsection{El humor auténtico nos devuelve al mundo corriente para mejorarlo}

Critchley defiende que las diminutas explosiones de humor que llamamos chistes tienen dos funciones:

1.- Nos devuelven a un mundo corriente, familiar, de prácticas compartidas, de significados implícitos en el trasfondo de una cultura.

2.- Nos señalan que esas prácticas podrían transformarse $\mathrm{O}$ perfeccionarse, que las cosas podrían ser de otra manera.

La risa, por tanto, tiene para este autor un poder redentor o mesiánico.

Según Critchley, el humor no nos redime de este mundo, sino que nos devuelve a él al mostrarnos que no hay alternativas, que éste es el único mundo. Al mostrarnos la locura del mundo, el humor no nos salva de esa locura desviando nuestra atención a otra parte, sino que nos llama a enfrentarnos a la locura del mundo y cambiar la situación en la que nos encontramos.

\subsection{El humor es universal pero arraigado en lo local, $y$ ha de saber utilizarse para criticar $y$ mejorar éticamente las propias costumbres.}

\section{1.- El humor nos permite criticar nuestras costumbres como si las viéramos desde fuera}

El humor es una constante antropológica, universal y común a todas las culturas, pues no se ha descubierto ninguna sociedad sin humor.

Es una de las condiciones para adoptar una posición crítica respecto a lo que se considera vida cotidiana. Es una forma de antropología social crítica, que desmitologiza lo exótico e invierte la noción del sentido común que tenemos en nuestra sociedad.

El humor es una práctica que nos da una perspectiva extraña de nuestras prácticas. Nos deja ver el mundo como si hubiéramos llegado de otro planeta. El cómico es el antropólogo de nuestras monótonas vidas cotidianas. 
2.- El humor es universal, aunque en cada cultura puede haber códigos diferentes sobre lo que se ríe.

La mayoría de los estudios sobre el humor, los chistes y lo cómico entienden que el humor es universal. Al parecer nunca ha habido culturas sin risa, aunque la variedad y la intensidad del humor difieran dramáticamente.

Pero el humor utiliza normalmente un lenguaje que es local y el sentido del humor suele tener un contexto bastante específico. Por eso el humor es terriblemente difícil de traducir. Salvo las comedias mudas, como las de Chaplin o Mr. Bean, el humor verbal es difícil de traducir. Y un chiste explicado es un chiste estropeado.

Critchley (2010: 92) escribe: «El humor es una forma de conocimiento cultural del miembro de un grupo y, de hecho, podríamos decir que es eficaz como mecanismo de defensa lingüística». Tener un sentido común del humor es como compartir un código secreto.

$\mathrm{Al}$ escuchar un chiste presupongo un mundo social compartido, con cuyas formas la práctica del chiste se dispone a jugar. Por eso, en ocasiones, se fracasa al intentar contar un chiste en una lengua extranjera. Wittgenstein (1980: 83) lo señala así: «¿Qué supone para las personas no tener el mismo sentido del humor? No reaccionan debidamente entre sí».

El humor nos devuelve a la condición física y la animalidad, también nos devuelve a la localidad, a un ethos específico y circunscrito. Nos devuelve al lugar del que venimos, ya sea un vecindario concreto o la abstracción de un Estado-nación. El sentido del humor es a menudo lo que nos une de la manera más fuerte a un lugar específico.

3.- Desde nuestra cultura en ocasiones utilizamos el bumor como superioridad para criticar a los miembros de otras culturas.

El ethos del lugar se expresa, a menudo, al reírnos de quienes no son como nosotros. En Inglaterra a los irlandeses suele describírseles como estúpidos y a los escoceses como sagaces. Los franceses se ríen de los belgas, los belgas de los holandeses y éstos les devuelven la risa.

El «humor étnico» es la risa de superioridad criticada por Hobbes (1992: 46) o la gloria repentina por nuestra eminencia ante la estupidez ajena.

4.- El uso ético del humor, arraigado en lo local, consistiría en utilizarlo como crítica de nosotros mismos y de nuestro propio pueblo.

El humor es lo que nos devuelve a lo local, a un ethos específico que con frecuencia se identifica con un pueblo en particular que posee una serie de costumbres y características compartidas. En opinión de Critchley no deberíamos esquivar la naturaleza relativista del humor, 
pero no para concluir que, por lo tanto, «todo vale», sino para utilizarlo como una herramienta pegada a nuestra realidad contextual, capaz de lanzar las críticas oportunas a nuestras costumbres cotidianas. Así es como parece entender la función del humor cuando nos pide que tengamos el valor de asumir «nuestro provincianismo».

Cuando reímos de nuestro propio pueblo el humor nos dice entonces algo de lo que somos, y puede ser también un recordatorio de que tal vez no seamos la persona o el pueblo que nos gustaría ser.

Una vez comprobado que el «humor ético» contribuye a transformar nuestra sociedad, la última característica que es importante atribuirle es la de orientar correctamente. Habría, por tanto, que recordar la importancia de «reír con razón».

\section{Vittorio Hösle: Reír con razón}

\subsection{Es importante analizar el objeto de nuestra risa para poder justificarla}

Vittorio Hösle (2002), después de revisar diversas teorías acerca de la risa, especialmente la clasificación de D. H. Monro (1951), concluye que, para una visión normativa del humor, lo importante es atender a la cualidad del objeto cómico o ridículo o de la situación cómica o ridícula en sí, por eso considera poco relevantes las teorías que discuten aspectos de los receptores (como la teoría de la superioridad o la teoría de la liberación de la tensión).

Para Hösle sólo la percepción de que algo no se corresponde con lo que debería ser en sentido ético puede ser el fundamento de una teoría normativa de lo cómico. Así, escribe: «si queremos responder a la cuestión de si nuestra risa es inteligente o no, nuestra sensación de superioridad justificada o no, no podemos evitar analizar el objeto de la risa» (Hösle, 2002: 22).

La risa es una dolorosa sanción negativa de conductas socialmente inaceptables (como, por ejemplo, la vanidad), aunque carezca de la brutalidad de la violencia física y de los riesgos vinculados a ella. Por eso, es un eficaz medio para mostrar desaprobación sin elevados costes para el que lo emplea. La cuestión clave, para una ética del humor, es que esa sanción que expresa la risa está justificada con las razones adecuadas. 


\subsection{La risa será moralmente aceptable si nos identificamos de algún modo con el objeto.}

Para considerar moralmente aceptable la risa, un hombre civilizado exigirá que se atenúe el sentimiento de superioridad. El reidor inteligente tiene que reconocer que el sujeto del que se ríe no es básicamente distinto de él. Él mismo puede poseer algunos de los rasgos caricaturizados.

En la risa cultivada hay cierta identificación melancólica con su objeto, cuando ésta falta el que ríe se vuelve repugnante o incluso objeto de escarnio él mismo. Un ejemplo de esa cierta identificación con el objeto se produce cuando sonreímos ligeramente antes de empezar a reír: «el reidor que primero sonríe pide en cierto sentido perdón por aquello que se dispone a hacer» (Hösle, 2002: 28).

\subsection{Reímos con razón cuando la conducta objeto de la risa merece evitarse}

Hösle (2002: 30) escribe: «La persona objeto de risa tiene que merecer nuestro escarnio, porque su desdicha es una justa consecuencia de su conducta y porque su conducta infringe ciertas normas intelectuales o morales que es preciso reconocer».

$\mathrm{Y}$ añade: «Reímos con razón cuando nos sentimos superiores con razón, y nos sentimos superiores con razón cuando la conducta objeto de la risa es de hecho algo que habría que evitar» (Hösle, 2002: 31).

El problema es la determinación de qué tipo de conductas deberían evitarse y, por lo tanto, elaborar un listado de aquello que con razón nos debería hacer reír, con su correspondiente justificación teórica. Hösle no realiza esta tarea y considera que nadie la ha conseguido realizar.

\section{Conclusiones}

El humor ético contribuye al equilibro del ser humano consigo mismo y con los demás, porque fomenta una actitud positiva ante la vida, respetuosa con uno mismo y con los demás. Es importante, por ello, investigar y mostrar los rasgos que configuran una ética del humor.

Para empezar, han abierto el camino para pensar sobre el fenómeno del humor desde las diversas teorías éticas que se han dado en la historia, ya pongan el punto de referencia en la intención o en la responsabilidad o en ambas. Podríamos clasificar las diversas éticas en diversos grupos o 
categorías, y que desde todas esas categorías podríamos hacer aportaciones para una ética del humor.

Teniendo en cuenta las aportaciones de autores que han escrito sobre el humor desde una perspectiva ética, como es el caso de Ronald de Sousa, Joseph Boskin, John Morreall, Simon Critchley y Vittorio Hösle, me aventuro a señalar que, entre los rasgos de la ética del humor, se encuentran los siguientes:

\section{1.- Ayuda a reconocer los valores éticos en los que realmente creemos}

La risa es un síntoma que manifiesta la personalidad o el carácter de quien ríe. La ética del humor tiene un gran potencial para evaluar éticamente las actitudes de quien ríe. Y en la medida en que las actitudes están fuertemente asentadas, puede contribuir a desenmascarar las verdaderas creencias morales y a criticarlas cuando corresponda, con un gran potencial, por tanto, de transformación social.

\section{2.- Detecta el humor éticamente incorrecto que mantiene estereotipos}

El humor en ocasiones se ha utilizado también para fomentar estereotipos negativos de una parte de la población o de minorías étnicas. Personalmente entiendo que la ética del humor debe criticar ese uso, pues se trata de un humor malicioso. Frente a ello, se ha de fomentar un humor que rompa estereotipos y anime al conocimiento de las diversas culturas y al respeto mutuo.

\section{3.- Fomenta el desarrollo de virtudes}

Fomenta el desarrollo de virtudes, tanto intelectuales (del pensamiento) como éticas (del carácter). Nos pide practicar el humor en el momento y lugar correcto, y en el grado adecuado. Entre las virtudes éticas que fomenta el humor se encuentran las siguientes: paciencia, tolerancia, amabilidad, humildad, perseverancia, y coraje.

\section{4.- Critica los vicios de la sociedad y contribuye a construir una sociedad más} ética

Critica vicios generales de la sociedad, y los que ríen al percibir la comicidad de esos vicios reciben una importante lección moral que les lleva a pensar sobre si ellos mismos están actuando de ese modo, ayudándoles a corregirse para evitar resultar risibles.

Nos lleva a expresarnos con libertad y también nos ayuda a actuar de acuerdo con el tipo de persona que realmente queremos ser. Nos devuelve al mundo corriente, cotidiano, real, para descubrir los puntos criticables arraigados en nuestra sociedad y nos anima a construir una sociedad más ética. Busca el consenso de los que ríen para mejorar la 
sociedad en el sentido de eliminar lo que es risible por ser moralmente incorrecto.

5.- Justifica con razones adecuadas la risa que trata de mejorar éticamente a la sociedad

Analiza el objeto de nuestra risa para poder justificar éticamente dicha risa. Fomenta que nos identifiquemos, de algún modo, con el objeto de nuestra risa, es decir, que nos pongamos en el lugar de aquellos que son objeto de la risa, para no exagerar nuestra crítica. Entiende que reímos con razón cuando la conducta objeto de la risa merece justificadamente evitarse.

\section{REFERENCIAS}

-Allport, G. (1954). The Nature of Prejudice. Garden City, NY: Doubleday \& Co. -Apel, K.-O. (1985). El a priori de la comunidad de comunicación y los fundamentos de la ética. En K.-O. Apel, La transformación de la filosofía (Vol. II, págs. 341-415). Madrid: Taurus.

-Basu, S. (1999). 'Woe unto you that laugh now!': Humor and toleration in Overton and Shaftesbury. En J. C. Laursen (Ed.), Religious toleration. The varieties of rites' from Cyrus to Defoe (págs. 147-172). New York: St. Martin's Press.

-Beauchamp, T. L. \& Childress, J. F. (1999). Principios de ética biomédica. Barcelona: Masson.

-Bergson, H. (2008). La risa. Ensayo sobre la significación de lo cómico. Madrid: Alianza.

-Boskin, J. (1987). The Complicity of Humor: The Life and Death of Sambo. En J. Morreall (Ed.), The Philosophy of Laughter and Humor (págs. 250-263). New York: State University of New York Press.

-Carbelo, B. (2008). El bumor en la relación con el paciente. Una guía para profesionales de la salud. Barcelona: Elsevier-Masson.

-Cortina, A. \& Martínez, E. (1998). Ética. Madrid: Akal.

-Cortina, A. \& Conill, J. (Dirs.) (2000). 10 palabras clave en ética de las profesiones. Estella-Navarra: Verbo Divino.

-Correa, M. \& Martínez, P. (Eds.) (2010). La riqueza ética de las profesiones. Santiago de Chile: RIL editores.

-Critchley, S. (2010). Sobre el humor. Torrelavega: Quálea.

-De Sousa, R. (1987). When Is It Wrong to Laugh? En J. Morreall (Ed.), The Philosophy of Laughter and Humor (págs. 226-249). New York: State University of New York Press.

-Garanto, J. (1983). Psicología del humor. Barcelona: Herder.

-Griffiths, T. (1976). Comedians. London: Faber. 
-Hobbes, T. (1992). Leviatán. O la materia, forma y poder de una República eclesiástica y civil. Buenos Aires: FCE de Argentina.

-Hösle, V. (2002). Woody Allen. Filosofía del humor. Barcelona: Tusquets.

-Lipman, S. (1991). Laughter in Hell. The use of humor during the Holocaust. Northvale NJ: Jason Aronson.

-Lippmann, W. (1922). Public Opinion. New York: Macmillan.

-Martin, R. A. (2008). La psicología del humor. Madrid: Orión.

-Monro, D. H. (1951). Argument of laughter. Melbourne: Melbourne University Press.

-Morreall, J. (Ed.) (1987). The Philosophy of Laughter and Humor. Albany-New York: State University of New York Press.

-Morreall, J. (2009). Comic Relief. A Comprehensive Philosophy of Humor. Malden, MA: Wiley-Blackwell.

-Morreall, J. (2010). Comic Vices and Comic Virtues. Humor: International Journal of Humor Research, 23 (1), 1-26.

-Siurana, J. C. (2003). Una brújula para la vida moral. Granada: Comares.

-Siurana, J. C. (2012a). Filosofía del humor. Estado de la cuestión. Diálogo Filosófico, (82), 4-33.

-Siurana, J. C. (2012b). Fundamentos para una ética del humor. En E. Casaban Moya (Ed.), XIX Congrés Valencià de Filosofia (págs. 473-484). Valencia: Societat de Filosofia del País Valencià.

-Siurana, J. C. (2013). Libertad, justicia y neurociencias en el final de la vida desde la ética del humor. En F. J. López Frías y otros (Eds.), Bioética, Neuroética, Libertad y Justicia (págs. 845-866). Granada: Comares.

-Wittgenstein, L. (1980). Culture and V alue. Oxford: Blackwell.

Sumario: Introducción; 1. El sentido del humor ético como equilibrio con uno mismo y con los demás; 1.1. El humor percibe o muestra lo cómico, provocando hilaridad; 1.2. El sentido del humor ético es una actitud positiva ante la vida; 1.3. El sentido del humor ético contribuye a la armonía con uno mismo y con los demás; 2. Ronald de Sousa: La risa refleja las actitudes de una persona; 2.1. La emoción de la hilaridad puede ser éticamente evaluada; 2.2. La risa refleja el carácter de una persona; 2.3. No podemos reír maliciosamente de alguien si nuestro carácter es ético; 2.4. Incluso cuando reímos solos imaginamos a otros riendo con nosotros, compartiendo nuestros valores morales; 2.5. La risa éticamente incorrecta está basada en valores éticamente incorrectos; 3. Joseph Boskin: El humor ético evita mantener estereotipos; 3.1. Un estereotipo es una imagen mental muy simple, no crítica y con capacidad de mantenerse tenazmente sobre el pensamiento racional; 3.2. El estereotipo cómico de Sambo; 4. John Morreall: Las virtudes del humor; 4.1. La ética positiva del humor; 4.2. El humor en el marco de la ética de las virtudes; 4.3. Las virtudes éticas que promueve el humor; 5. Simon Critchley: el humor auténtico como crítica a los vicios generales; 5.1. El chiste auténtico nos hace más libres y transforma la sociedad; 5.2. El humor auténtico critica los vicios generales, no los personales; 5.3. El humor auténtico nos devuelve al mundo 
corriente para mejorarlo; 5.4. El humor es universal pero arraigado en lo local, y ha de saber utilizarse para criticar y mejorar éticamente las propias costumbres; 6. Vittorio Hösle: Reír con razón; 6.1. Es importante analizar el objeto de nuestra risa para poder justificarla; 6.2. La risa será moralmente aceptable si nos identificamos de algún modo con el objeto; 6.3. Reímos con razón cuando la conducta objeto de la risa merece evitarse; Conclusiones; Referencias. 